\title{
Influence of spectral properties of light sources on perceived and recorded images
}

\author{
Jacek Kusznier
}

\author{
Facultyof Electrical Engineering, Bialystok Universityof Technology, Wiejska 45D, 15-351 Bialystok
}

Received May 27, 2021; accepted June 30, 2021; published June 30, 2021

\begin{abstract}
The text presents differences between the mechanism of seeing and recording images and potential sources of errors in color reproduction in recorded images. The measurements show that despite the relatively high values of indices $\left(R_{a}, R_{f} i R_{g}\right)$ not all tested lamps are suitable for use on a photo set, as indicated by the value of TLCI index. The lighting requirements on a film set prioritize the quality of color reproduction, even at the expense of reducing the Luminous efficacy of a source (LES) value.
\end{abstract}

Quality requirements for lighting of a shooting set are significa ntly different from those for general illum in ation. This is due to a different mechanism of image record ing with devices based on a rray detectors than the human visual sense. There are a total of five types of photoreceptors on the retina. Four of these a re responsible for eliciting visual sensations. Each of the photore ce ptor types is distinguished by different spectral sensitivity characteristics (Fig. 1). [1-3] The ra diation has a different effect on different organisms and on man-made detectors. [4-6]

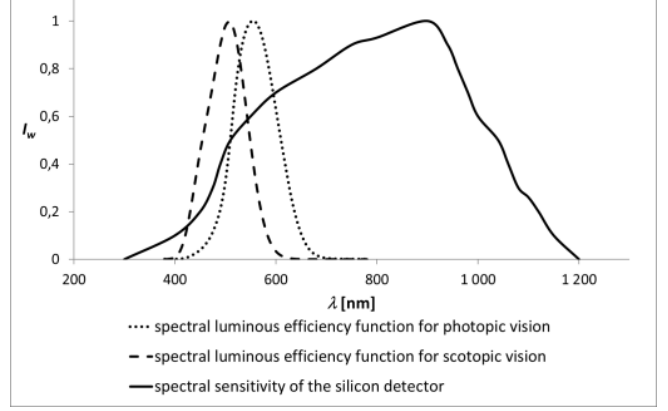

Fig. 1. Relative spectral characteristics: spectral luminous efficiency in photopic and scotopic vision and spectral sensitivity of the silicon detector.

The different spectral sensitivity characteristics of the rods and cones, together with additional mechanisms related to changes in pupil size, allow for a wide range of adaptations in the visual process to changing light conditions that occur in natural light. In lighting technology similar mechanisms of change are accomplished in smart lighting systems [7-13]. The three types of cones that are responsible for producing visual impressions in seeing a re characte rized by different spectral sensitivity ranges, which allow us to perceive colors. However, they require a lot of light, which means that we can only see colors correctly during the day. At low light levels during scotopic vision, only the rods remain active, which have a higher sensitivity but do not allow us to record color impressions. The issues of spectral sensitivity and the ability to record colors with the sense of sight are therefore very complex and depend on the sta te of visual a daptation.

Considering the issues presented, the International Commission on Illumination(CIE) a s a $\mathrm{n}$ international standardization body has defined the exact waveforms of spectral luminous efficiency in photopic and scotopic vision for a standard observer. This is described by two curves $\mathrm{V}(\lambda)$ and $\mathrm{V}^{\prime}(\lambda)$ (Fig. 1$)$.

This is somewhat of a simplification since the sense of sight is subject to constant a dap tation to chan ging lighting and environmental conditions. However, the introduction of the concept of a standard observer is necessary to evaluate the effects of ra diation on the observer. It must be remembered that this applies only to man as an observer.

The maximum luminous efficacy of radiation (LER) in photopic vision is $683 \mathrm{~lm} / \mathrm{W}$ and is achieved at a wa velength of $555 \mathrm{~nm}$.

$$
L E R=\frac{683 \frac{l m}{W} \int_{\lambda} V(\lambda) P_{o p t}(\lambda) d \lambda}{\int_{\lambda} P_{o p t}(\lambda) d \lambda}
$$

Striving to achieve the highest possible LER value lea ds light source manufacturers to narrow the light spectrum emitted by the sources. This is beca use thera diation at the edge of the visible spectrum, both in the violet and blue color range as well as in the red, is characterized by low LER values. Reducing the white light spectrum from 380$780 \mathrm{~nm}$ to $400-700 \mathrm{~nm}$ covers $99.93 \%$ of the optical energy below spectral luminous efficiency function for photopic vision. However, limiting the spectral width results in lower values of the color rendering index. However, in order to en sure that colors can be reproduced correctly, it is necessary to use sources who se emission covers the entire visible range as far as possible.

The LER of white light sources can therefore reach a maximum value of $520 \mathrm{~lm} / \mathrm{W}$. The lines of the maximum LER values in the CIE1931 dia gram are shown in Fig. 2. [14-18].

The luminous efficacy of a source (LES) will a lwa y s be less than the LER since only part of the electrical power is converted into radiation. 




Fig. 2. Contours of maximum possible luminous efficiency of radiation shown on CIE 1931 chromaticity diagram (adapted from MacAdam 1950, Schelle 2014)

The mechanism of recording images with a rray detect ors is to reproduce, as far as possible, the impressions that we perceive with our sense of sight in the process of daytime vision. Semiconductor detectors currently used in im a ge recording technology are based on silicon $(\mathrm{Si})$, whose spectral sensitivity is different from $\mathrm{V}(\lambda)$ a nd a dditionally extends beyond the visible range (Fig. 1).

To enable human-like color reproduction, a grid of color filters is applied to the array detector, resulting in the individual pixels of the array recording a signal only within a narrow range of the selected color. The most commonly used is the RGB color system. Another technique that allows to record color images is the use of three a rrays. In this case, each sensor receives light of a different primary color (RGB) that is split by a n optical system.

In addition, all pixels on an array detector a re distrib u ted evenly a cross its surface, which is also different from the distribution of photoreceptors on the retina. The dissimila rity between the human sense of sight and the array detector led to the need to define a new index.

The standard observer's model created by CIE is not suitable for modern recording devices and set lighting. [19] As a result, the color rendering indexes defin ed for lighting did not allow the evaluation of light sources in set lighting and television production in a meaningful way . This resulted in the need for costly and time-consuming color corrections in the recorded images. The previously used color rendering index es proved to be insufficient in the case of LED and fluorescent sources. The development of a mathematical model of a standard camera became necessary in the field of lighting qu ality analysis for TV and photo graphy.

In 2012, TheEuropean Broadcasting Union ap proved a new index for determining the quality of lighting fixture s used to illuminate sets in television productions. This parameter was called Television Lighting Consistency Index 2012 (TLCI-2012). The purpose of defining this parameter wa s to create the concept of a standard came ra in contrast to the concept of a standard observer. The model created was adapted to the spectral sensitivity characteristics of modern HDTV cameras [21-23].

The model of a standard camera was used, whose spectral characteristics taking into account the entire optical path including the lens and the gamma correction performed as well as the non-linear electrooptic transferfunction of the display is shown in Fig. 3.

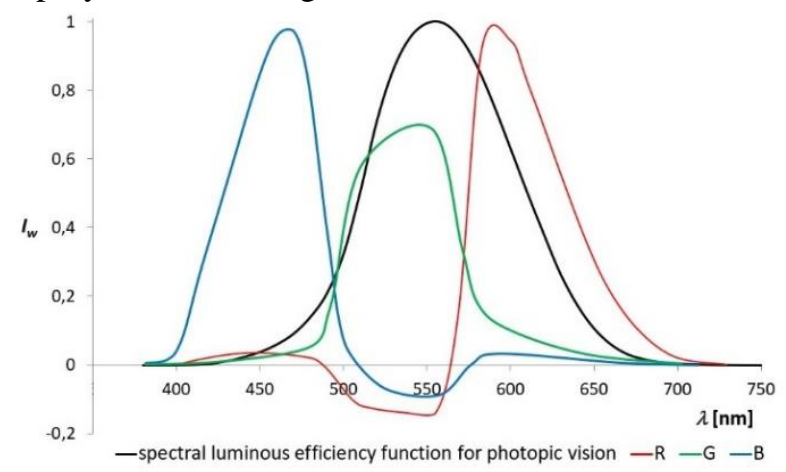

Fig. 3. Spectral luminous efficiency in photopic vision and TLCI-2012 Camera with adjusted Matrix (developed on the basis of [21-23]).

The discussed issues are presented in the results of comparative analy sis carried out for selected light sources (Fig. 5, Table 1).

The spectral character of light sources (halogen, fluorescent and LED) depends on the way of obtaining white light (Fig. 4). The first way is to mix the streams emitted by the three red, green and blue sources.[24] This allows, with appropriate control LED, to change the spectral properties of the emitted light. The techniq ue of mixing the ra diation of theblue LED with the radiation of the yellow phosphor is also often used.

A StellarNet Blue-Wave UVIS-50 spectrometer was used for the measurements. The results were calculated in a calculation sheet and in the ColorCalculator v. 7.77 program.

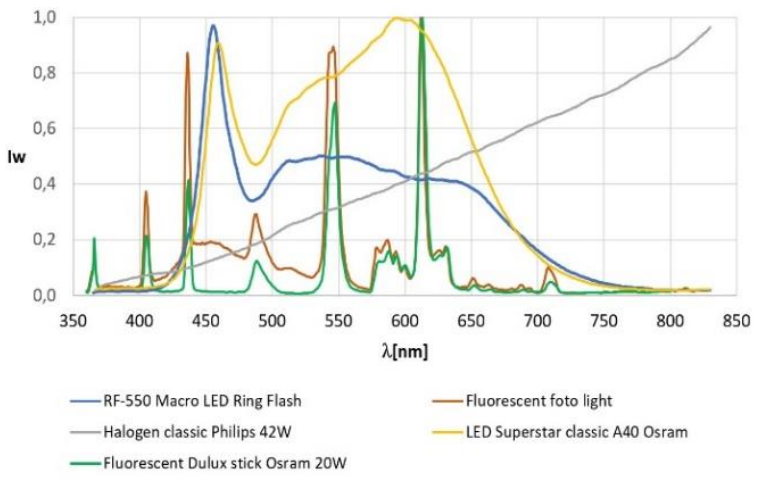

Fig. 4. Spectral power distribution of the measured lamps. 


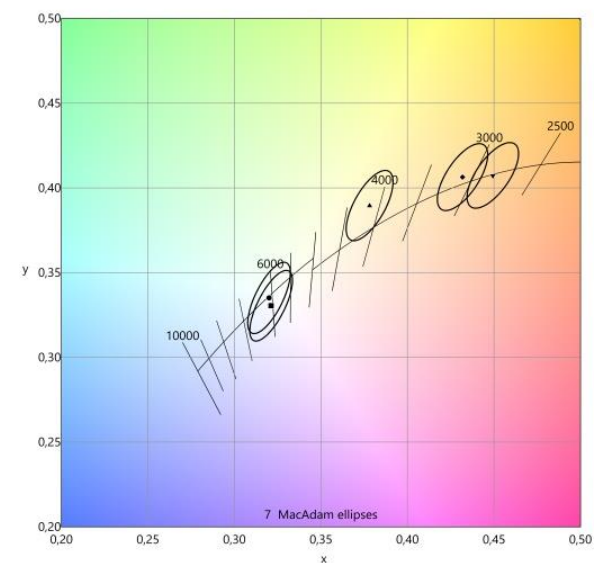

Fig. 5. Positions of the point on the chromaticity graph tested light sources (based on own research).

Tab. 1. Measured index values of selected lamps (based on own research)

\begin{tabular}{|c|c|c|c|c|c|c|c|}
\hline & $\begin{array}{c}\text { CCT } \\
{[\mathrm{K}]}\end{array}$ & $\mathbf{R a}$ & $\mathrm{R} 9$ & $\mathrm{R}_{12}$ & $\begin{array}{c}\text { Rf } \\
\text { IES } \\
\text { TM } \\
30-18\end{array}$ & $\begin{array}{c}\text { Rg } \\
\text { IES } \\
\text { TM } \\
30-18\end{array}$ & TLCI \\
\hline $\begin{array}{c}\text { RF-550 } \\
\text { Macro LED } \\
\text { Ring Flash }\end{array}$ & 6089 & $\mathbf{9 5}$ & 85 & 71 & $\mathbf{9 2}$ & $\mathbf{9 9}$ & $\mathbf{9 7}$ \\
\hline $\begin{array}{c}\text { Fluorescent } \\
\text { foto light }\end{array}$ & 6050 & $\mathbf{8 7}$ & 66 & 73 & $\mathbf{8 5}$ & $\mathbf{1 0 3}$ & $\mathbf{7 2}$ \\
\hline $\begin{array}{c}\text { Halogen } \\
\text { classic } \\
\text { Philips42W }\end{array}$ & 3107 & $\mathbf{9 9}$ & 96 & 98 & $\mathbf{9 9}$ & $\mathbf{1 0 0}$ & $\mathbf{1 0 0}$ \\
\hline $\begin{array}{c}\text { LED } \\
\text { Superstar } \\
\text { classic A40 } \\
\text { Osram }\end{array}$ & 4153 & $\mathbf{8 6}$ & 17 & 66 & $\mathbf{8 5}$ & $\mathbf{9 1}$ & $\mathbf{7 5}$ \\
\hline $\begin{array}{c}\text { Fluorescent } \\
\text { Dulux stick } \\
\text { Osram 20W }\end{array}$ & 2830 & $\mathbf{8 3}$ & 10 & 51 & $\mathbf{7 5}$ & $\mathbf{1 0 4}$ & $\mathbf{4 7}$ \\
\hline
\end{tabular}

The measurements show that despite the relatively high values of indices $\left(R_{a}, R_{f} i R_{g}\right)$ not all tested lamps are suitable for use on a photo set, as indicated by the value of TLCI index.

The lighting requirements on a film set prioritize the quality of color reproduction, even at the expense of reducing the luminous efficacy of a source(LES) value.

The standard camera model and TLCI-2012 index had to be created due to the non-human white balance mechanism in cameras. The use of array detectors in digital devices versus classical basic silver halide photosensitive materials created problems mainly in the near infrared $(750-1100 \mathrm{~nm})$. Radiation at these wavelengths is used in consumer devices to increase apparent sensitivity in low light conditions. However, this is at the expense of degraded color reproduction. Th is is because LED sources have different levels of IR radiation com pared to tungsten lighting. Color reproduction errors in lower cost devices a re due to poor filtering of radiation, particularly in the IR range.

This research was funded by the Bialystok University of Technology as part of the work WZ/WE-IA/3/2020.

\section{References}

[1] L.T. Sharpe, A. Jagla, W. Jägle, J. Vision 5(11), 948 (2012)

[2] K. Mangold, J.A. Shaw, M. Vollmer, Eur. J. Phys. 34, 51 (2013)

[3] M.P. Simunovic, Arch. Ophthalmol. 130(7), 919 (2012).

[4] M. Gilewski, Phot. Lett. Poland 11(3), 87 (2019).

[5] M. Gilewski, Phot. Lett. Poland 11(4), 115 (2019).

[6] I. Fryc, E. Czech, Opt. Eng. 41(10), 2402 (2002). https://doi.org/10.1117/1.1503344

[7] L. Bellia, U. Blaszczak, F. Fragliasso, L. Gryko, Solar Energy 208, 830 (2020).

[8] J. Kusznier, W. Wojtkowski, Impact of climatic conditions on PV panels operation in a photovoltaic power plant, IEEE 15 th Selected Issues of Electrical Engineering and Electronics (WZEE), Zakopane, Poland (2019).

[9] J. Kusznier, W. Wojtkowski, Impact of climatic conditions and solar exposure on the aging of PV panels, IEEE 15th Selected Issues of Electrical Engineering and Electronics (WZEE), Zakopane, Poland (2019).

[10] J. Fan, Y. Li, I. Fryc, C. Qian, X. Fan, G. Zhang, IEEE Photon. J. 12(1), 1 (2020); Art no. 8200218,

[11] M. Gilewski, L. Gryko, A. Zajac, Proc. SPIE 8902, 89021D (2013).

[12] J. Kusznier, W. Wojtkowski, Phot. Lett. Poland 12(1), 16 (2020).

[13] J. Kusznier, Changes in the Spectral Power Distribution of Light Sources for Smart Lighting, IEEE 14th WZEE (2018).

[14] H.F. Ivey, J. Opt. Soc. Am. 53, 1185 (1963).

[15] F. Zhang, H. Xu, Z. Wang, Appl. Opt. 56, 1962 (2017).

[16] T.W. Murphy Jr. J. Appl. Phys. 111, 104909 (2012). https://doi.org/10.1063/1.4721897

[17] P.-C. Hung, J.Y. Tsao, J. Display Technol. 9, 405 (2013).

[18] V.M. Lisitsyn, V.S. Lukash, S.A. Stepanov, Ju Yangyang, AIP Conf. Proc. 1698, 060008 (2016); doi.org/10.1063/1.4937863

[19] J. Kowalska, I. Fryc, Przeglad Elektrotechniczny R. 95(7), 94 (2019).

[20] I. Fryc, J. Fryc, A. Wasowski, Przeglad Elektrotechniczny R. 92(2), 218 (2016); doi: 10.15199/48.2016.02.55

[21] TECH 3353, Development of a "standard" television camera model implemented in the TLCI-2012, Source: FTV-LED, EBU, Geneva November 2012

[22] TECH 3354, Comparison of CIE colour metrics for use in the television lighting consistency index (TLCI-2012), Source: FTVLED, EBU, Geneva November 2012

[23] TECH 3355, Method for the assessment of the colorimetric properties of luminaires the television lighting consistency index (TLCI-2012) and the television luminaire matching factor (TLMF2013), Source: FTV-LED Geneva March 2017

[24] J. Kusznier, Przeglad Elektrotechniczny R. 84(8), 182 (2008). 